\title{
Identificação do potencial amilolítico de linhagens mutantes do fungo filamentoso Aspergillus nidulans
}

\author{
Identification of the amylolytic potential of mutant strains of the filamentous fungi Aspergillus nidulans
}

Izabel Aparecida SOARES ${ }^{2 \star}$, Andressa Caroline FLORES ${ }^{1,2}$, Luana ZANETTIN ${ }^{1,2}$, Heloana Karoline PIN ${ }^{2}$, Marcos Marques MENDONÇA², Rodrigo Patera BARCELOS ${ }^{2}$, Luciane Regina TREVISOL ${ }^{2}$, Rosimere Domingos CARVALHO ${ }^{2}$, Dionéia SCHAUREN ${ }^{2}$, Carmem Lucia de Mello Sartori Cardoso da ROCHA ${ }^{2}$, Suzymeire BARONI ${ }^{2}$

\section{Resumo}

As amilases estão entre as mais importantes enzimas industriais, apresentando grande importância biotecnológica, principalmente na indústria alimentícia. Com o avanço no conhecimento das enzimas, a utilização dos fungos como fonte de enzimas vem adquirindo um status de destaque nas mais variadas áreas industriais e comerciais. Diante disso, o presente estudo procurou identificar a presença de atividade amilolítica em quatro linhagens do fungo filamentoso Aspergillus nidulans, selvagem, PAT, biA1methG1 e CLB3, utilizando dois meios distintos de cultura, BDA e Meio Completo a $2 \%$ amido, variando os tratamentos com adição ou não de glicose. Foram determinados o diâmetro médio da colônia, o diâmetro médio do halo e o Índice Enzimático. Como resultados, todas as linhagens testadas foram capazes de degradar o amido quando na ausência de glicose, porém o tratamento que obteve estatisticamente melhor crescimento e maior degradação do amido foi o MC sem glicose a $2 \%$ amido e a linhagem que se demonstrou potencialmente degradadora de amido foi o mutante CLB3. Conclui-se, portanto, que Aspergillus nidulans pode ser considerado como um produtor de amilases.

Palavras-chave: enzimas; amilase; fungos; biotecnologia.

\begin{abstract}
The amylases are among the most important industrial enzymes showing great biotechnological importance, mainly in the food industry. Due to the advance knowledge in enzyme research, the use of fungi as source of enzymes has acquired a prominent status in most varied industrial and commercial areas. Thus, the present study tried to identify the presence of the amylolytic activity in four stains of filamentous fungi Aspergillus nidulans, selvagem, PAT, biA1meth G1 and CLB3 by using two different culture means, PDA and Complete mean with $2 \%$ starch, varying the treatments with and without the addition of glucose. The colony average diameter, the halo average diameter, and the enzymatic index were determined. The results show that all strains tested were capable of degrading starch in the absence of glucose although the treatment that presented statistically better growing and bigger degradation of starch was CM without glucose with $2 \%$ starch and the strain that demonstrated potentially degradation was CLB3 mutant. It was concluded that Aspergillus nidulans can be considered as an enzyme producer.
\end{abstract}

Keywords: enzymes; amylases; fungi; biotechnology.

\section{Introdução}

Enzimas são substâncias naturais envolvidas em todos os processos bioquímicos, que dentre outras funções, são capazes de decompor moléculas complexas em unidades menores, como carboidratos em açúcares (OLIVEIRA; MULLER; SEGATO, 2004).

Devido à característica de especificidade das enzimas, cada substrato possui uma enzima respectiva. No caso do amido, principal polissacarídeo de reserva dos vegetais, são as amilases as responsáveis pela sua quebra. Essas enzimas amilolíticas atuam na quebra das ligações glicosídicas presentes nas cadeias de amilose e amilopectina (LIN; HSU; CHU, 1997; GUPTA et al., 2003).

As amilases estão entre as mais importantes enzimas industriais, apresentando grande importância biotecnológica, tais como aplicações nas indústrias têxteis, cervejas, bebidas destiladas, panificação, cereais para alimentação infantil, liquefação e sacarificação do amido, ração animal, indústria química e farmacêutica. Apesar de poderem ser derivadas de diversas fontes, incluindo plantas, animais e microrganismos, enzimas microbianas geralmente encontram grande demanda industrial. Atualmente, grandes quantidades de amilases microbianas estão disponíveis comercialmente e têm aplicação quase completa na hidrólise do amido em indústrias de processamento do amido (GUPTA et al., 2003; PANDEY et al., 2005).

A aplicação de microrganismos como as bactérias, leveduras e principalmente os fungos, dentro da indústria alimentícia, resulta atualmente em uma indústria extremamente diversificada e com rendimentos econômicos consideravelmente

Recebido para publicação em 24/6/2008

Aceito para publicação em 8/7/2009 (003591)

${ }^{1}$ Biologia, Universidade Paranaense - UNIPAR, Toledo - PR, Brasil

2 Ciências Biológicas, Universidade Paranaense - UNIPAR, CEP 85903170, Toledo-PR, Brasil, E-mail: belcbio@gmail.com

${ }^{*}$ A quem a correspondência deve ser enviada 
altos. Exemplos clássicos de processos microbiológicos são as fermentações, destacando a produção de bebidas alcoólicas e álcool etílico, laticínios, ácidos orgânicos e fármacos, incluindo os antibióticos. Outros produtos de origem microbiana considerados importantes são alguns polímeros de aplicação industrial, moléculas estereoespecíficas produzidas através de biotransformação, aditivos alimentares (aminoácidos) e vitaminas (OMURA, 1992). Harki e Rakshist (2003) também trazem como exemplo a produção de enzimas termorresistentes por microrganismos extremófilos.

O gênero Bacillus é um dos mais importantes e investigados grupos de bactérias produtoras de amilase comercial. Porém, as principais fontes biológicas de enzimas são os fungos filamentosos que perfazem $60 \%$, em contraste com as bactérias, $24 \%$; animal, 6\%; planta, 4\%; levedura, 4\%; e Streptomyces, 2\% (PANDEY et al., 2000; ZAKS; DOODS, 1998).

Com o avanço no conhecimento das enzimas, os fungos vêm adquirindo um status de destaque para vários tipos de indústrias uma vez que existe a possibilidade de utilizá-las para melhorar vários aspectos do produto final.

A engenharia genética tem um papel importante na produção de enzimas uma vez que pode ser usada para introduzir pequenas mudanças na sequência genética do fungo, visando produzir enzimas similares às originais, mas com propriedades alteradas. Pode também ser usada para introduzir genes de organismos originais em organismos produtores (hospedeiros), produzir novas linhagens ou ainda produzir "enzimas puras" sem outras atividades que possam interferir de uma maneira indesejável no produto (ARCHER; MACKENZI; JEENES, 2001).

Conforme Wainwright (1995), existem cerca de 200 espécies de Aspergillus, comumente isolados do solo, de plantas em decomposição e do ar. As espécies de Aspergillus produzem um grande número de enzimas extracelulares, muitas das quais são aplicadas na biotecnologia. Dentre as espécies mais conhecidas, encontram-se o Aspergillus flavus, A. niger, A. oryzae, A. nidulans, A. fumigatus, A. clavatus, A. glaucus, A. ustus e o A. versicolor. Os Aspergillus spp. pertencem ao reino Fungi, filo Ascomycota, ordem dos Eurotiales, família Trichocomaceae e gênero Aspergillus. Pertencem também ao grupo dos hyalihyphomyces, os quais formam esporos. Suas colônias podem apresentar coloração branca, rosada, amarela, amarelo-esverdeada, amarronzada ou verde. A taxa de crescimento destes fungos é rápida a moderadamente rápida.

Esse trabalho teve como objetivo analisar o potencial amilolítico de linhagens de Aspergillus nidulans e comparar a atividade amilolítica de linhagens selvagens e mutantes dessa espécie.

\section{Material e métodos}

Para testar o potencial de quebra do amido, utilizou-se o mutante CLB3, e três linhagens (selvagem, PAT e biA1methG1) de Aspergillus nidulans. Foi utilizado o Meio Completo (MC), segundo Pontecorvo et al. (1953), a 2\% amido, com e sem adição de glicose e meio Batata Dextrose Ágar (BDA) com e sem adição de dextrose, ambos preparados em $\mathrm{pH}$ 6,0. As linhagens foram devidamente rejuvenescidas e repicadas em placas de petri com os respectivos meios.
As placas inoculadas permaneceram em estufa incubadora sob temperatura de $37^{\circ} \mathrm{C}$ para crescimento durante cinco dias. Após o crescimento, as placas foram retiradas para a medição do diâmetro das colônias com o auxílio de um paquímetro. Para a identificação de atividade amilolítica, adicionaram-se em cada placa $3 \mathrm{~mL}$ de tintura de iodo. Instantaneamente, uma zona amarelada ao redor da colônia indicou presença de degradação de amido. A área amarelada é denominada halo de hidrólise. Logo após o procedimento, realizou-se a medição do diâmetro dos halos formados.

A atividade enzimática foi determinada pelo método de Hankin e Anagnostakis (1975) através da relação entre o diâmetro médio do halo de degradação e o diâmetro médio da colônia, expresso como Índice Enzimático (IE).

Para detectar diferenças nos valores médios dos tratamentos arranjados ao acaso, os dados de três repetições foram submetidos à análise de variância seguido do teste de Tukey, considerando um delineamento estatístico de blocos casualizados.

\section{Resultados e discussão}

Do ponto de vista prático, existem várias propostas para determinar a atividade enzimática por difusão radial em meio sólido. Os fatores determinantes que viabilizam esta seleção incluem a correlação direta entre o tamanho do halo e a capacidade degradativa dos microrganismos (CESKA, 1971; LIN; CHANG; SHEN, 1991; NETO; CUNHA, 1987).

Para considerar um microrganismo bom produtor de enzimas extracelulares em meio sólido, Lealem e Gashe (1994) indicaram um índice enzimático maior ou igual a 2,0. Neste experimento as linhagens demonstraram valores de $\mathrm{IE}<2,0$ (Tabela 1). Isso poderia indicar um baixo potencial enzimático. Entretanto, as linhagens testadas, quando mantidas refrigeradas a $4{ }^{\circ} \mathrm{C}$ durante 10 dias, continuaram retirando do meio de cultivo os nutrientes de que necessitavam, quebrando então o amido ainda disponível. Pode-se considerar então, as hipóteses de que a refrigeração pode melhorar a ação das amilases ou então proporcionar uma condição estressante para o fungo, de forma que ele degrada e consome mais compostos do que o normal. Partindo desse princípio, sugere-se um maior estudo para verificar se há maior desempenho na degradação do amido quando as linhagens são acondicionadas sob temperatura baixa durante alguns dias.

O dado apresentado acima contradiz Fellows (1994) que relata que a atividade enzimática ótima das enzimas microbianas ocorre nas mesmas condições em que se produz o crescimento máximo dos microrganismos. Sabe-se que a maioria dos estudos de produção de amilases foi realizada a partir de fungos mesofílicos dentro da faixa de temperatura de 25 a $37{ }^{\circ} \mathrm{C}$. Rendimentos ótimos de $\alpha$-amilase foram alcançados entre 30 e $37^{\circ} \mathrm{C}$ para Aspergillus sp., $30^{\circ} \mathrm{C}$ para $A$. niger na produção da amiloglucosidase (COSTA, 1996); $30{ }^{\circ} \mathrm{C}$ para a produção de $\alpha$-amilase por A. oryzae (TUNGA, R.; TUNGA B. S., 2003); $55{ }^{\circ} \mathrm{C}$ pelo fungo termofílico Thermomonospora; e a $50{ }^{\circ} \mathrm{C}$ por T. lanuginosus na produção de $\alpha$ - amilase (GUPTA et al., 2003). Entretanto, não há relatos de que se tenha testado o aumento da atividade enzimática após crescimento do fungo nas condições ideais e refrigeração de $4{ }^{\circ} \mathrm{C}$ por 10 dias. 
Considerando que o meio descrito na literatura como ideal para o crescimento de Aspergillus nidulans é o Meio Completo (MC), os dados obtidos demonstram um crescimento e formação de halo de hidrólise maiores do que os obtidos em meio Batata Dextrose Ágar (BDA), no qual o crescimento da maioria das amostras não foi satisfatório. Quanto ao desempenho de cada linhagem, os resultados mostram que a selvagem, considerada como controle, demonstrou resultados satisfatórios quanto à degradação do amido, principalmente nos meios em que não havia glicose disponível. Realizando uma comparação da selvagem com as demais linhagens, observa-se que a linhagem PAT foi a que mais se assemelhou ao controle, seguida da linhagem biA1methG1. O mutante CLB3 deve ser analisado separadamente, pois, segundo descrito por Rocha (1997), possui características peculiares como, por exemplo, tamanho da colônia reduzido.

Sendo assim, os valores obtidos na degradação do amido em MC sem glicose a $2 \%$ amido são menores do que as outras linhagens testadas como se observa na Figura 1, porém mais significativos, levando em consideração o menor tamanho da

Tabela 1. Comparações de médias de Índices Enzimáticos (IE) expressos em centímetros das linhagens mutantes de Aspergillus nidulans crescidas em diferentes meios de cultivo, pH 6,0 sob refrigeração e sem refrigeração.

\begin{tabular}{|c|c|c|c|c|c|c|c|c|c|c|c|}
\hline Linhagem & Meio de cultura & \multicolumn{5}{|c|}{ IE sem refrigeração } & \multicolumn{5}{|c|}{ IE sem refrigeração } \\
\hline \multirow{3}{*}{ biAlmeth $\mathrm{G} 1$} & MC sem glicose & 1,19 & $\mathrm{a}$ & & & & 1,55 & $\mathrm{a}$ & & & \\
\hline & MC com glicose & 0 & & $\mathrm{~b}$ & & & 1,16 & & $\mathrm{~b}$ & & \\
\hline & BDA sem glicose & 0 & & $\mathrm{~b}$ & & & 0,25 & & & c & \\
\hline \multirow{5}{*}{ PAT } & BDA com glicose & 0 & & $\mathrm{~b}$ & & & 0,55 & & & & $\mathrm{~d}$ \\
\hline & MC sem glicose & 1,22 & $\mathrm{a}$ & & & & 1,48 & $\mathrm{a}$ & & & \\
\hline & BDA sem glicose & 0,2 & & $\mathrm{~b}$ & & & 1,39 & & $\mathrm{~b}$ & & \\
\hline & BDA com glicose & 0 & & & c & & 1,16 & & & c & \\
\hline & MC com glicose & 0 & & & c & & 0,73 & & & & $\mathrm{~d}$ \\
\hline \multirow{3}{*}{ CLB3 } & MC sem glicose & 1,18 & a & & & & 1,3 & $\mathrm{a}$ & & & \\
\hline & BDA sem glicose & 0 & & $\mathrm{~b}$ & & & 1,25 & & $\mathrm{~b}$ & & \\
\hline & MC com glicose & 0 & & $\mathrm{~b}$ & & & 1,18 & & & $\mathrm{c}$ & \\
\hline \multirow{5}{*}{ Selvagem } & BDA com glicose & 0 & & $\mathrm{~b}$ & & & 0,54 & & & & $\mathrm{~d}$ \\
\hline & MC sem glicose & 1,32 & $\mathrm{a}$ & & & & 1,4 & $\mathrm{a}$ & & & \\
\hline & BDA sem glicose & 1,02 & & $\mathrm{~b}$ & & & 1,25 & & $\mathrm{~b}$ & & \\
\hline & MC com glicose & 0,7 & & & c & & 0,92 & & & $\mathrm{c}$ & \\
\hline & BDA com glicose & 0 & & & & $\mathrm{~d}$ & 0,51 & & & & d \\
\hline
\end{tabular}

Meio Completo (MC), Batata Dextrose Ágar (BDA). Letras iguais correspondem a dados estatisticamente iguais ao nível de 5\% de significância pelo teste de Tukey.

Sem refrigeração

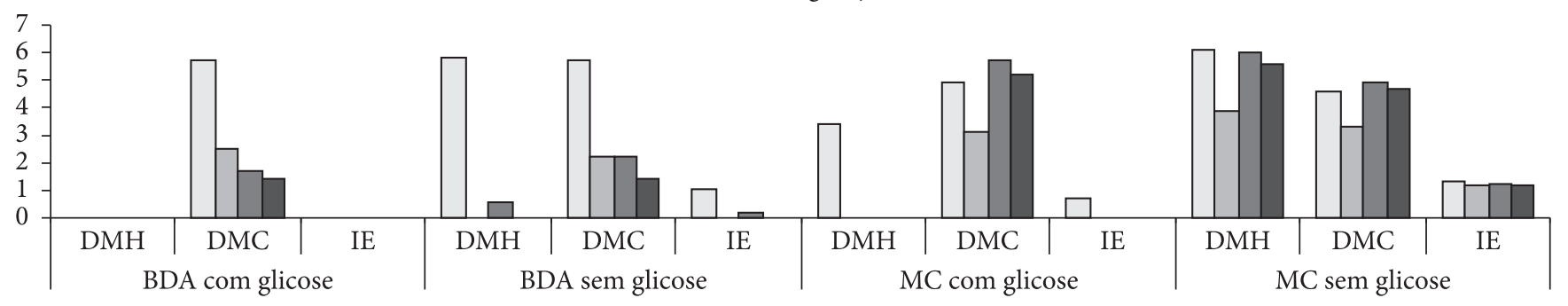

Com refrigeração

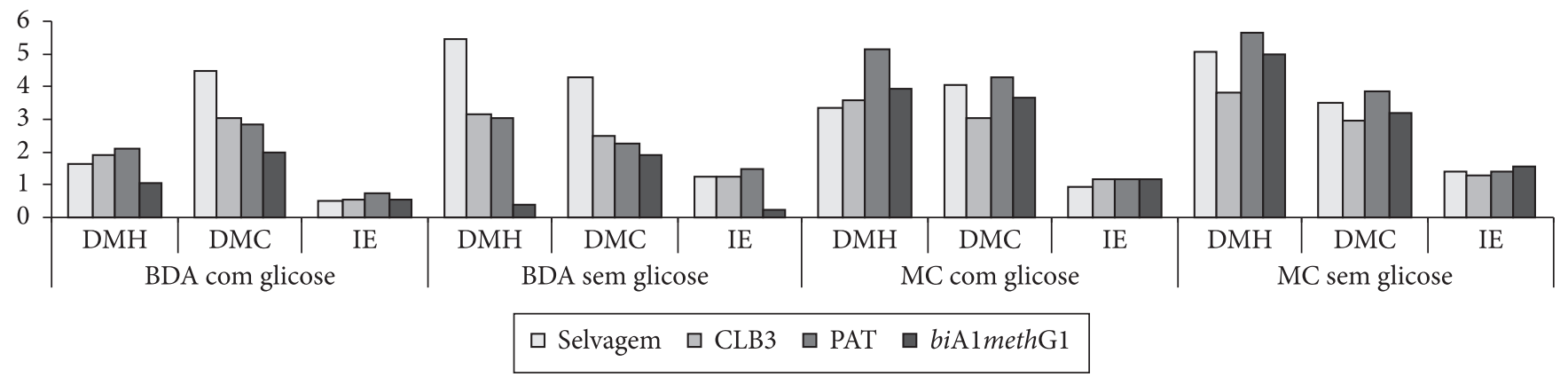

Figura 1. Gráfico comparativo para os valores de Diâmetro Médio do Halo (DMH), Diâmetro Médio da Colônia (DMC) e Índice Enzimático (IE) das linhagens mutantes de Aspergillus nidulans sob condição sem refrigeração e com refrigeração a $4{ }^{\circ} \mathrm{C}$ durante 10 dias em Meio Completo (MC) e Batata Dextrose Ágar (BDA). 
colônia do mutante. O fato do mutante CLB3 apresentar dados estatísticos mais significativos também pode ser visualmente comprovado quando comparado às imagens dos tamanhos dos halos formados (Figura 2).

A avaliação das fontes de carbono revelou que todas as linhagens testadas foram hábeis em degradar o amido. Algumas linhagens de microrganismos são capazes de degradar tanto $\alpha$-amilases como glicoamilases, como observado
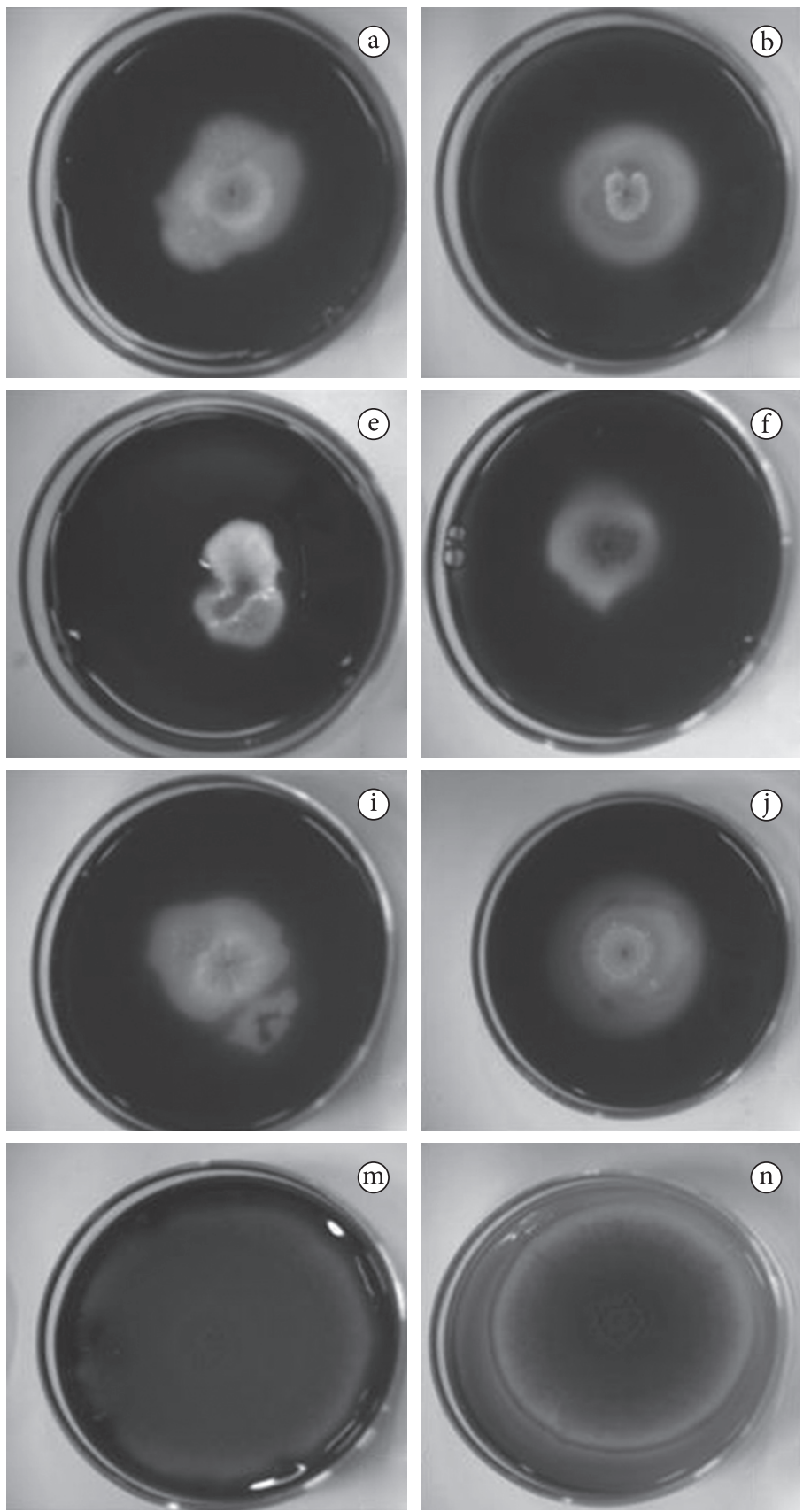

por Moraes (2004) em Aspergillus niger. A glicose é uma fonte de carbono facilmente metabolizada e esse fato pode fazer com que o microrganismo consuma primeiramente a glicose sem que haja a necessidade de expressão de enzimas específicas e, posteriormente, com o esgotamento dessa fonte, o microrganismo passe a expressar enzimas específicas, para que possa metabolizar outra fonte de carbono presente no meio. Provavelmente, a expressão inicial de amilases em fontes
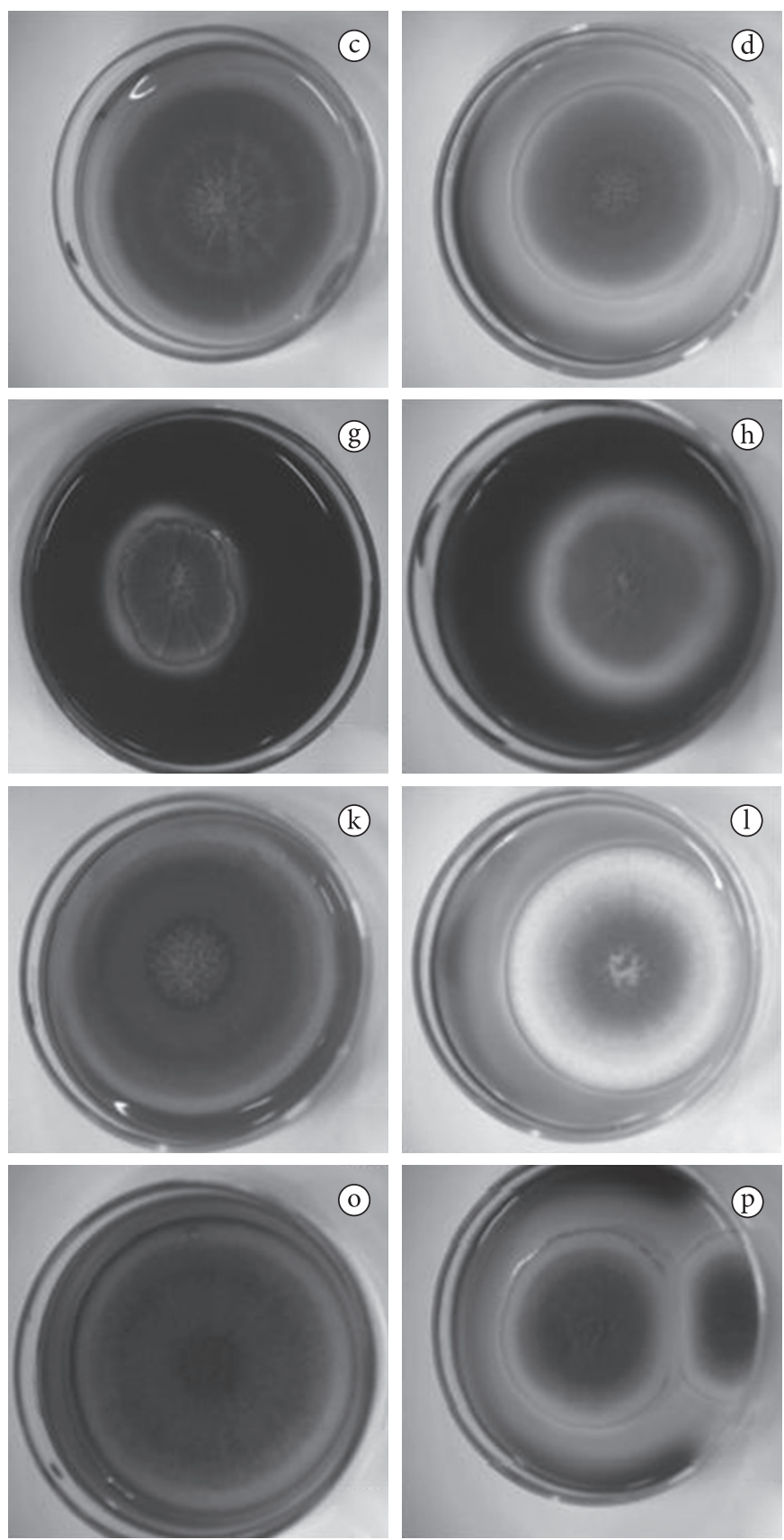

Figura 2. Formação de halo após adição da tintura de iodo em linhagens mutantes de Aspergillus nidulans mantidas em diferentes meios de cultura. a) biA1methG1 - Batata Dextrose Ágar glicose; b) biA1methG1 - Batata Dextrose Ágar sem glicose; c) biA1methG1 - meio completo + amido; d) biA1methG1 - meio completo sem glicose + amido; e) CLB3 - Batata Dextrose Ágar com glicose; f) CLB3 - Batata Dextrose Ágar sem glicose; g) CLB3 - meio completo + amido; h) CLB3 - meio completo sem glicose + amido; i) PAT - Batata Dextrose Ágar com glicose; j) PAT - Batata Dextrose Ágar sem glicose; k) PAT - meio completo + amido; l) PAT - meio completo sem glicose + amido; m) selvagem Batata Dextrose Ágar com glicose; n) selvagem - Batata Dextrose Ágar sem glicose; o) selvagem - meio completo + amido; p) selvagem - meio completo sem glicose + amido. 
de carbono como o amido juntamente com a glicose poderia ocorrer posteriormente (MONTEIRO; ULHOA, 2006). A alta densidade celular e a alta taxa de crescimento específico podem ser obtidas com glicose, mas alta atividade específica e produção de enzimas são obtidas com o amido (PANDEY et al., 2000).

Todos os resultados indicaram que as linhagens testadas são capazes de degradar o amido presente no meio de cultivo quando na ausência de glicose. Ressaltam-se os resultados obtidos com o tratamento MC sem glicose a $2 \%$ amido que demonstraram ser estatisticamente diferentes dos valores dos demais tratamentos.

Fungos podem utilizar o amido como fonte de energia para o crescimento e esporulação. No entanto, a produção de amilase por fungos filamentosos varia de acordo com o gênero e a espécie envolvida (DIANESE, 1990; GRIFFIN, 1994; NWUFO; FAJOLA, 1988). Inúmeros fatores de natureza biológica ou físico-química podem influenciar no número e atividade enzimática dos micro-organismos (SANOMIYA; NAHAS, 2003; MACCHERONI JUNIOR; ARAÚJO; AZEVEDO, 2004).

De acordo com Pandey et al. (1999, 2005), as enzimas amilolíticas também são produzidas por fungos filamentosos, sendo preferidas as espécies de Aspergillus e Rhizopus. Wainwright (1995) e Pandey et al. (2005) descrevem que espécies como o Aspergillus niger, A. oryzae, A. awamori, Fusarum oxysporum, Humicola insolens, Mucor pusillus, Trichoderma viride são espécies produtoras de $\alpha$-amilase, e Aspergillus niger, A. fumigatus, A. saitri, A. terreus, A. foetidus e Rhizopus foetidus, $R$. delemer são espécies de fungos utilizadas para a produção de amiloglucosidase, assim como Soccol et al. (2005) destacam que a amiloglucosidase (glucoamilase), na maioria das vezes, é produzida principalmente por fungos dos gêneros Aspergillus sp., Rhizopus sp. e Endomyces sp.

Diversos são os microrganismos produtores de $\alpha$-amilase e amiloglucosidase, destacando-se as espécies dos gêneros Aspergillus, Rhizopus, Bacillus que têm sido empregadas em processos industriais (COSTA, 1996; PANDEY et al., 2005). Ward (1989) afirma que, enquanto a maltose parece ser o melhor indutor para a a-amilase de A. oryzae, o amido, a maltose e a glucose estimulam a produção de amiloglucosidase por $A$. niger. Fellows (1994) relata que as preparações comerciais de amilases fúngicas que contêm pequenas proporções de fosfatase, glucoamilase e protease sacarificam mais profundamente o amido que a amilase e dão lugar a quantidades substanciais de maltose que contêm apenas glucose.

São utilizadas para os seguintes processos: eliminam a turbidez produzida pelos amidos e reduzem a viscosidade dos sucos de frutas; transformam o amido de cacau em dextrinas, reduzindo assim sua viscosidade e melhorando os xaropes de chocolate; reduzem a viscosidade da massa de panificação e aceleram a fermentação dessas massas pelas leveduras. Dentre as amilases fúngicas, as que apresentam maior interesse industrial são: $\alpha$-amilase, $\beta$-amilase; amiloglucosidase e dextrinase limite (HARGER; SPRADA; HIRATSUKA, 1982).

\section{Conclusões}

Conclui-se, portanto, que todas as linhagens analisadas demonstraram potencial de quebra do amido. Uma das linhagens mutantes, CLB3, revelou-se boa produtora de amilases tendo em vista o tamanho do halo formado em relação ao seu tamanho reduzido. As linhagens quando mantidas sob refrigeração demonstram atividade amilolítica acelerada.

\section{Referências bibliográficas}

ARCHER, D. B.; MACKENZI, D. A.; JEENES, D. J. Genetic engineering: yeasts and filamentous fungi. In: RATLEDGE, C.; KRISTIANSEN, B. Basic Biotechnology. Cambridge, United Kingdom: Cambrige University Press, 2001. p. 95-126.

CESKA, M. Enzyme catalysis of solidified media. European Journal Biochemistry, v. 22, p. 186-192, 1971.

COSTA, J. A. V. Estudo da Produção de Amiloglucosidase por Aspergillus níger NRRL 3122 em Fermentação Semi-Sólida de Farelo de Arroz. 203 f. Tese(Doutorado em Engenharia de Alimentos)-Universidade Estadual de Campinas, Campinas, 1996.

DIANESE, J. C. Patologia vegetal: agressão e defesa em sistemas plantapatógeno. Brasília: Editora Universidade de Brasília, 1990.

FELLOWS, P. Tecnología del procesado de los alimentos: princípios e práticas. Zaragoza: Editorial Acribia, 1994. p. 172-177.

GRIFFIN, D. H. Fungal physiology. [S.1.]: John Willey \& Sons Incorporation, 1994. $458 \mathrm{p}$.

GUPTA, R. et al. Microbial $\alpha$-Amylases: Biotechnological Perspective. Process Biochemistry, v. 38, n. 11, p. 1-18, 2003.

HANKIN, L.; ANAGNOSTAKIS, S. L. The use of solid media for detection of enzyme production by fungi. Mycologia, v. 67, p. 597-607, 1975.

HARGER, C.; SPRADA, D.; HIRATSUKA, E. Amilase fúngica. In: Bioquímica das fermentações. [S.1.]: [s.n.], 1982. 56 p.

HARKI, G. D. and RAKSHIST, S. K. Developments in industrially important thermostable enzymes: a review. Bioresource Technology, v. 89, p. 17-34, 2003.

LEALEM, F.; GASHE, B. A. Amylase production by a gram-positive bacterium isolated from fermenting tef (Eraglostis tef). Journal of Applied Bacteriology, v. 77, p. 348-352, 1994.

LIN, J. E.; CHANG, D. C. N.; SHEN, G. J. Correlations among several screening methods used for identifying wood-decay fungi that can degrade toxic chemicals. Biotechniques, v. 5, n. 4, p. 275-280, 1991.

LIN, L. L.; HSU, W. H.; CHU, W. S. A gene encoding for an a-amylase from thermophilic Bacillus sp. Strain TS-23 and its expression in Escherichia coli. Journal Applied Microbiology, v. 82, n. 3, p. 325-334, 1997.

MACCHERONI JUNIOR, W.; ARAÚJO, W. L.; AZEVEDO, J. L. Ambient $\mathrm{pH}$-regulated enzyme secretion in endophytic and pathogenic isolates of the fungal genus Colletotrichum. Scientia Agricola, v. 61, n. 3, p. 298-302, 2004.

MONTEIRO, V. N.; ULHOA, C. J. Biochemical Characterization of a $\beta-1,3$ Glucanase from Trichoderma koningii Induced by Cell Wall of Rhizoctonia solani. Current Microbiology, v. 52, p. 92-96, 2006.

MORAES, L. M. P. Amilases. In: SAID, S.; PIETRO, R. Enzimas como agentes biotecnológicos. Ribeirão Preto: Legis Summa, 2004.

NETO, J. A.; CUNHA, B. C. de A. Método rápido para a triagem de fungos amilolíticos e seus mutantes. Revista de Microbiologia, v. 18 , p. $264-268,1987$. 
NWUFO, M. I.; FAJOLA, A. O. Production of amylolytic enzymes in culture by Botryodiplodia theobromae and Sclerotium rolfsii associated with the corn rots of Colocasia esculenta. Acta Microbiologica Hungarica, v. 35, p. 371-378, 1988.

OLIVEIRA, C.; MULLER, F.; SEGATO, M. Departamento de Engenharia Química e de Alimentos. Aplicações de enzimas em produtos de limpeza. In: Trabalhos de graduação do grupo de processos biotecnológicos da UFSC. Florianópolis: Universidade Federal de Santa Catarina, 2004. Disponível em: <http://www.enq. ufsc.br/labs/probio/disc_eng_bioq/trabalhos_grad2004/detergente/ enzimas_produtos_limpeza.htm>. Acesso em: 2 jan. 2008.

OMURA, S. The expanded horizon for microbial metabolites - a review. Gene, v. 115, n. 1-2, p. 141-149, 1992.

PANDEY, A. et al. Advances in microbial amylases. Biotechnology and Applied Biochemistry, v. 31, n. 2, p. 135-152, 2000.

PANDEY, A. et al. Enzyme Technology. 1. ed. New Delhi: Asiatech Publishers, 2005.

PANDEY, A. et al. Solid State Fermentation for the Production of Industrial Enzymes. Current Science, v. 77, n. 1, p. 149-161, 1999.

PONTECORVO, G. et al. The genetics of Aspergillus nidulans. Advances in Genetics, v. 5, p. 141- 238, 1953.
ROCHA, C. L. M. S. C. Caracterização citológica, genética e molecular de um mutante para conidiogênese em Aspergillus nidulans. Tese (Doutorado em Genética e Melhoramento de Plantas)-Escola Superior de Agricultura "Luiz de Queiroz", Universidade de São Paulo, Piracicaba, 1997.

SANOMIYA, L. T.; NAHAS, E. Microorganismos produtores de hidrolases envolvidos nas transformações dos compostos do carbono e do nitrogênio do solo. Ciência Rural, v. 33, n. 5, p. 835-842, 2003.

SOCCOL, C. R. et al. Glucoamylase. In: Enzyme technology. New Delhi: Asiatec Publishers, 2005. p. 221-230.

TUNGA, R.; TUNGA, B. S. Extra-cellular Amylase Production by Aspergillus oryzae Under Solid State Fermentation. Japan: International Center for Biotechnology, Osaka University, 2003. 12 p.

WAINWRIGHT, M. Introducción a la Biotecnología de los Hongos. Zaragoza: Acribia, 1995

WARD, O. Biotecnologia de la fermentación: princípios, procesos e productos. Zaragoza: Acribia, 1989. p. 64-67 e 233-247.

ZAKS, A.; DOODS, D. R. Biotransformation in the discovery and developmente of pharmaceuticals. Current Opinion in Drug Discovery \& Development, v. 1, p. 290-303, 1998. 